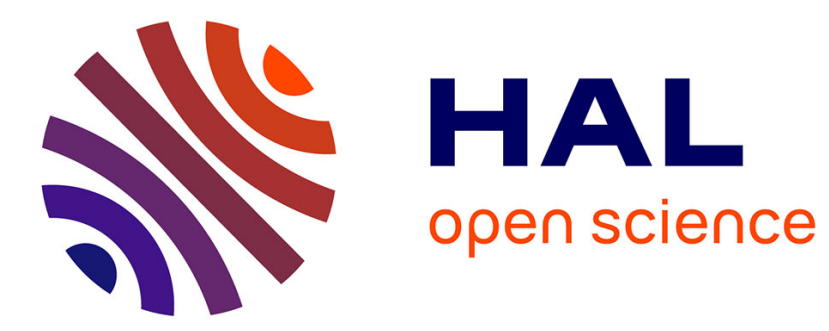

\title{
New insights into the taxonomy of the genus Buthus Leach, 1815 in Jordan and description of a new species (Scorpiones: Buthidae)
}

Wilson R Lourenço, Abu Afifeh, Mohammad Al-Saraireh, Mohammad Abu Baker, Zuhair Amr

\section{To cite this version:}

Wilson R Lourenço, Abu Afifeh, Mohammad Al-Saraireh, Mohammad Abu Baker, Zuhair Amr. New insights into the taxonomy of the genus Buthus Leach, 1815 in Jordan and description of a new species (Scorpiones: Buthidae). Zoology in the Middle East, 2021, 67 (2), pp.168-176. 10.1080/09397140.2021.1908507 . hal-03268512

\section{HAL Id: hal-03268512 \\ https://hal.sorbonne-universite.fr/hal-03268512}

Submitted on 23 Jun 2021

HAL is a multi-disciplinary open access archive for the deposit and dissemination of scientific research documents, whether they are published or not. The documents may come from teaching and research institutions in France or abroad, or from public or private research centers.
L'archive ouverte pluridisciplinaire HAL, est destinée au dépôt et à la diffusion de documents scientifiques de niveau recherche, publiés ou non, émanant des établissements d'enseignement et de recherche français ou étrangers, des laboratoires publics ou privés. 


\section{New insights into the taxonomy of the genus Buthus Leach, 1815 in Jordan and description of a new species (Scorpiones: Buthidae)}

Wilson R. Lourenço ${ }^{\mathrm{a}}$, Bassam Abu Afifeh ${ }^{\mathrm{b}}$, Mohammad Al-Saraireh ${ }^{\mathrm{c}}$, Mohammad Abu Baker $^{\mathrm{d}}$, Zuhair Amr

aMuséum national d'Histoire naturelle, Sorbonne Universités, Institut de Systématique, Evolution, Biodiversité (ISYEB), UMR7205-CNRS, MNHN, UPMC, EPHE, CP 53, 57 rue Cuvier, 75005 Paris, France, e-mail: wilson.lourenco@mnhn.fr

${ }^{b}$ Ministry of Education, Al Rumman Secondary School, Amman, Jordan, e-mail: bassam_abu_afifeh@yahoo.com

'Oncology Department, Royal Medical Services, Amman, Jordan, e-mail: abohashem99m@gmail.com

${ }^{\mathrm{d} D e p a r t m e n t}$ of Biology, The Jordan University, Amman, Jordan, e-mail: Ma.Abubaker@ju.edu.jo

eDepartment of Biology, Jordan University of Science \& Technology, Irbid, Jordan, e-mail: amrz@just.edu.jo

Abstract. Following the first changes on the taxonomy of the genus Buthus Leach, proposed by Lourenço almost 20 years ago, an impressive number of new species have been described mainly from North Africa, some sub-Saharan regions and European countries. In contrast, very few new species were described from Middle East, basically one from Yemen and one from the South Jordan. In the present contribution a new species of Buthus is described from the south-western range of Jordan, The new species shows several common morphological features with Buthus amri Lourenço, Yağmur \& Duhem, 2010, described from the region of Aqaba suggesting that both species may correspond to vicariant elements of a common ancestry.

Key-words: Scorpion, Buthus, new species, Jordan, vicariant species. 


\section{Introduction}

Since the beginning of the 1950s, and in particular with the publication of the monographic work done by Vachon (1952) on the scorpion fauna of North Africa, and until the early 2000s the composition of the genus Buthus Leach, 1815 remained extremely conservative. The preliminary revisions proposed by Lourenço $(2002,2003)$ started to change the conservative view of the genus Buthus, and during the last 20 years an impressive number of new species have been described from North African deserts, sub-Saharan regions, but also from some European countries (see Lourenço et al., 2020). A first attempt to bring a global analysis of the genus Buthus was published by Sousa et al. (2017). This contribution in the form of a mini-catalogue, although having merits, is biased by a number of gaps. Most of the presented data is merely a compilation of previous publications and the majority of the original type material was not consulted.

The presence of the genus Buthus in Middle East countries is clearly more discrete than in African regions and has been for a long period represented only by Buthus israelis Shulov \& Amitai, 1959, known from Israel and Sinai (Levy \& Amitai, 1980). More recently a new species, Buthus yemenensis Lourenço 2008 was described from Yemen (Lourenço, 2008), and Buthus amri Lourenço, Yağmur \& Duhem, 2010 from the region of Aqaba, in Wadi Rum Desert of Jordan (Lourenço et al., 2010). More recently, one of the authors (B.A. Afifeh) collected 20 specimens of Buthus in the region of Petra, Jordan. A precise analysis of several morphological characters of this Buthus sample indicates a number of common morphological features with Buthus amri distributed in the region of Aqaba, suggesting the possibility that both populations may be vicariant elements of a common ancestry. The presence of 'sibling' or vicariant species has already been described in other buthid genera such as the genus Grosphus Simon, 1880 from Madagascar (Lourenço et al., 2018), further complicating the delimitation of related species. Nevertheless, the Buthus populations from 
Aqaba and Petra differ morphologically and inhabit distinctly different environments (see ecological section). Consequently, a new species is described for the Petra population.

\section{Material and Methods}

Illustrations and measurements were made with the aid of a Wild M5 stereomicroscope with a drawing tube (camera lucida) and an ocular micrometer. Photos were produced with the use of a Canon digital camera. Measurements follow Stahnke (1970) and are given in mm. Trichobothrial notations follow Vachon (1974) and morphological terminology mostly follows Vachon (1952) and Hjelle (1990). Holotype and paratypes will be deposited in the collections of the Muséum national d'Histoire naturelle, Paris, and of the University of Jordan, Amman, Jordan.

\section{Taxonomy}

Family Buthidae C. L. Koch, 1837

Genus Buthus Leach, 1815

Buthus amri Lourenço, Yağmur \& Duhem, 2010 (Fig. 1)

Buthus amri: Zool. Middle East: 96.

Aqaba, Wadi Rum Desert (2934’14” N - 35 17’00” E) 1010 m.

Diagnosis: A scorpion of medium size, reaching a total length of $44 \mathrm{~mm}$ in males and $50 \mathrm{~mm}$ in females. General coloration yellow to pale yellow; carinae of carapace intensely spotted; three longitudinal stripes over tergites; legs and pedipalps without spots. Carinae moderately to strongly developed; granulations moderate to weak on body and appendages. Fixed and movable fingers with 9 (10)-10 rows of granules. Pectines with 27 to 29 teeth in males, 21 to 23 on females. 
Buthus nabataeus sp. n. (Figs. 2-6)

Type Material. Holotype (female): - Jordan, Al-Baydah, $4 \mathrm{~km} \mathrm{~N}$ of Petra, Ma'an Governorate (30 24' 29.4” N - 35 27’ 36.8” E), 1257 m a.s.l, 15-16/X/2020 (Bassam Abu Afifeh leg.). Paratypes: 3 males, 1 female paratype deposited in the Muséum national d'Histoire naturelle, Paris. 5 males and 10 female paratypes deposited in University of Jordan Amman, Jordan.

Etymology: the specific name refers to the Nabataeans, the first people who lived in Petra.

\section{Diagnosis}

A scorpion of median to small size, reaching an average total length of $32 \mathrm{~mm}$ in males and $42 \mathrm{~mm}$ in females (Table I). General colouration yellow to pale yellow; carinae of carapace intensely spotted; tergites with one central longitudinal stripe and marked confluent spots laterally; legs and pedipalps pale yellow, without spots. Carinae strongly marked; granulations moderately to weakly marked; chelicerae with small denticles on the external-lateral surface; ventral carinae on metasomal segments II to $\mathrm{V}$ with huge spinoid granules, several with a lobular shape. Fixed and movable fingers with 9-10 rows of granules. Pectines with 26 to 28 teeth in males, 19 to 24 in females. Telson vesicle strongly bulked with the aculeus extremely short (Fig. 3). Trichobothrial pattern A-Beta, a priori orthobothriotaxic, however the trichobothrium Esb of chela-hand is absent in some females (Fig. 5).

Description based on female holotype and paratypes. Measurements in Table I.

Coloration basically yellow to pale yellow. Prosoma: Carapace yellowish with carinae and eyes marked by dark pigment. Mesosoma yellowish with one central longitudinal stripe and confluent spots laterally. Metasomal segments yellow with diffused spots over some carinae; spots better marked on segment $\mathrm{V}$; vesicle yellow with diffused spots laterally; aculeus yellow at its base and dark reddish at its extremity. Venter yellow; male sternites with diffused brown spots; pectines pale yellow. Chelicerae yellow to pale yellow without spots laterally; fingers yellow with blackish teeth. Pedipalps yellow; fingers with the oblique rows of granules dark reddish. Legs pale yellow without spots. 
Morphology. Carapace moderately granular; anterior margin almost straight. Carinae strongly marked; anterior median, central median and posterior median carinae strongly granular, with 'lyre' configuration. All furrows moderate to strong. Median ocular tubercle at the centre of carapace. Eyes separated by more than two ocular diameters. Three pairs of lateral eyes of moderate size; a fourth residual pair is also observed. Sternum triangular and narrow; wider than long. Mesosoma: tergites moderately granular. Three longitudinal carinae moderately crenulate in all tergites; lateral carinae reduced, almost absent in tergites I and II. Tergite VII pentacarinate. Venter: genital operculum divided longitudinally, which plate with a semi-oval to semi-triangular shape. Pectines: Pectinal tooth count 21-21 in female holotype (see diagnosis for variation); middle basal lamella of the pectines not dilated in both sexes. Sternites without granules, smooth with moderately elongated spiracles; four carinae on sternite VII; other sternites acarinated and with two weak furrows. Metasomal segments I to III with ten crenulated carinae, ventral strongly marked on segments II to V with huge lobate granules; segment IV with eight carinae, crenulated; the first four segments with a smooth dorsal depression; segment $\mathrm{V}$ with five carinae; the latero-ventral carinae crenulate with 4-5 lobate denticles posteriorly; ventral median carina only slightly divided posteriorly; anal arc composed of 6-7 ventral teeth, and two lateral lobes. Intercarinal spaces weaky granular, almost smooth. Body and appendages with a very marked setation. Telson with some granulations laterally and ventrally, other zones almost smooth; aculeus weakly curved and much shorter than the vesicle, without a subaculear tubercle. Cheliceral dentition as defined by Vachon (1963) for the family Buthidae; external distal and internal distal teeth approximately the same length; basal teeth on movable finger conspicuous and not fused; ventral aspect of both fingers and manus covered with long dense setae. Pedipalps; femur pentacarinate; patella with $7 / 8$ carinae; all faces weakly granular to smooth; chela smooth, with vestigial carinae. Fixed and movable fingers with 9-10 oblique rows of granules. Internal 
and external accessory granules present, strong; three accessory granules on the distal end of the movable finger next to the terminal denticle. Legs: Tarsus with two longitudinal rows of thin and long setae ventrally; tibial spur strong on legs III and IV; pedal spurs moderate on legs I to IV. Trichobothriotaxy: trichobothrial pattern of Type A, a priori orthobothriotaxic as defined by Vachon (1974), however trichobothrium Esb on chela-hand is absent in some females. Dorsal trichobothria of femur arranged in $\boldsymbol{\beta}$ (beta) configuration (Vachon, 1975).

\section{Relationships}

The key below shows the main difference among the four described species of the genus Buthus in the Middle East. Buthus nabataeus sp. n. can be distinguished from the other species of Buthus and in particular from B. amri by a number of characters: (i) B. amri is larger in overall size with males and females reaching total lengths of 46 and $52 \mathrm{~mm}$ (32 and $42 \mathrm{~mm}$ in $B$. nabataeus) (ii) pectines are bulker in the new species (iii) pectine pigmentation patterns differ; B. amri has three longitudinal stripes over the tergites while B. nabataeus sp. n. shows confluent spots (iv) carinae are more strongly marked in B. nabataeus sp. n. particularly the ventral carinae of metasomal segments II to $\mathrm{V}$; besides the new species shows small spinoid granules on the external-lateral face of chelicerae (v) trichobothrium Esb on chela-hand is absent or extremely reduced in some females of the new species. Finally, the species inhabit ecologically different habitats (see ecological section).

\section{Key to the confirmed Buthus species described from Middle East}

1. Scorpions of moderate to large size ranging from 50 to $70 \mathrm{~mm}$ in total length; females with 25 to 28 teeth on pectines; ventral carinae of metasomal segments moderate to weak .......2

Scorpions of small to moderate size ranging from 30 to $50 \mathrm{~mm}$ in total length; females with 19 to 24 teeth on pectines; ventral carinae of metasomal segments moderate to strong.......3

2. Number of rows in fixed and movable fingers of chela, 12-13; ventral carinae of metasomal segments weak; distribution Israel, Palestine and Jordan Buthus israelis 
Number of rows in fixed and movable fingers of chela, 10-10; ventral carinae of metasomal segments moderate; distribution Yemen Buthus yemenensis

3. Total length ranging from 40 to $50 \mathrm{~mm}$; ventral carinae of metasomal segments moderately marked; trichobothrium Esb always present Buthus amri

Total length ranging from 30 to $40 \mathrm{~mm}$; ventral carinae of metasomal segments strongly marked; trichobothrium Esb strongly reduced or absent on females Buthus nabataeus sp. n. 
Table I. Morphometric values (in mm) of the male holotypes and female paratype of Buthus amri and that of female holotype and paratype, and male paratypes of Buthus nabataeus sp. n.

\begin{tabular}{|c|c|c|c|c|c|}
\hline & \multicolumn{2}{|c|}{ Buthus amri } & \multicolumn{3}{|c|}{ Buthus nabataeus sp. $\mathrm{n}$} \\
\hline & $\hat{0}$ & 9 & $\hat{\delta}(n=2)$ & P $(\mathrm{n}=2)$ & 우 J \\
\hline Total length* & 44.3 & 49.7 & $40.7-43.7$ & $36.2-39.2$ & 28.0 \\
\hline \multicolumn{6}{|l|}{ Carapace } \\
\hline Length & 4.7 & 5.3 & $5.2-5.4$ & $4.3-4.5$ & 3.2 \\
\hline Anterior width & 3.5 & 4.2 & $3.9-3.9$ & $3.2-3.4$ & 2.3 \\
\hline Posterior width & 5.5 & 6.7 & $6.4-6.5$ & $5.1-5.2$ & 3.8 \\
\hline Mesosoma length & 12.6 & 15.7 & $9.9-11.2$ & $9-9.8$ & 8.3 \\
\hline \multicolumn{6}{|l|}{ Metasomal segment I } \\
\hline length & 3.6 & 3.5 & $3.3-3.5$ & $2.9-3.2$ & 2.1 \\
\hline width & 3.3 & 3.7 & $3.4-3.6$ & $3.0-3.5$ & 2.2 \\
\hline \multicolumn{6}{|l|}{ Metasomal segment II } \\
\hline length & 4.0 & 4.0 & $3.6-3.8$ & $3.4-3.7$ & 2.2 \\
\hline width & 3.1 & 3.2 & $3.1-3.3$ & $2.9-3.2$ & 2.0 \\
\hline \multicolumn{6}{|l|}{ Metasomal segment III } \\
\hline length & 4.2 & 4.1 & $3.9-4.0$ & $3.6-3.9$ & 2.3 \\
\hline width & 3.0 & 3.3 & $3.1-3.3$ & $2.8-3.2$ & 1.9 \\
\hline \multicolumn{6}{|l|}{ Metasomal segment IV } \\
\hline length & 4.6 & 4.8 & $4.3-4.6$ & $4.0-4.3$ & 3.1 \\
\hline width & 2.9 & 3.4 & $3.0-3.2$ & $2.7-2.9$ & 1.9 \\
\hline \multicolumn{6}{|l|}{ Metasomal segment V } \\
\hline length & 5.7 & 6.8 & $5.8-6.1$ & $4.9-5.4$ & 3.8 \\
\hline width & 2.8 & 3.2 & $2.8-3.0$ & $2.5-2.8$ & 1.9 \\
\hline depth & 2.1 & 2.5 & $2.1-2.3$ & $2.1-2.2$ & 1.6 \\
\hline \multicolumn{6}{|l|}{ Telson } \\
\hline length & 4.9 & 5.5 & $4.7-5.1$ & $4.1-4.4$ & 3.0 \\
\hline width & 2.3 & 2.9 & $2.8-3.0$ & $2.2-2.3$ & 1.7 \\
\hline depth & 2.1 & 2.5 & $2.7-2.6$ & $2.1-2.2$ & 1.5 \\
\hline \multicolumn{6}{|l|}{ Pedipalp } \\
\hline Femur length & 4.1 & 4.3 & $4.1-4.2$ & $3.7-4.0$ & 2.5 \\
\hline Femur width & 1.3 & 1.6 & $1.5-1.6$ & $1.2-1.3$ & 0.9 \\
\hline Patella length & 4.6 & 5.2 & $4.7-4.8$ & $4.2-4.6$ & 3.0 \\
\hline Patella width & 1.7 & 2.2 & $1.9-2.0$ & $1.6-2.0$ & 1.1 \\
\hline Chela length & 7.4 & 8.5 & $8.1-8.2$ & $7.0-7.5$ & 3.9 \\
\hline Chela width & 1.9 & 2.4 & $2.2-2.3$ & $1.8-2.0$ & 1.1 \\
\hline Chela depth & 2.0 & 2.6 & $2.4-2.4$ & $2.0-2.2$ & 1.2 \\
\hline Movable finger: length & 4.6 & 5.2 & $4.9-4.9$ & $4.2-4.5$ & 3.0 \\
\hline
\end{tabular}

* Including telson. 


\section{Ecological considerations}

Habitat of Buthus nabataeus sp. n. (Fig. 7)

The specimens of Buthus nabataeus sp. n. were collected from Petra area, an arid Mediterranean zone with sandstone formations and with relatively high rainfall precipitations (400 mm annually) and occasional snow. The area is semi-arid with remnants of the Phoenician juniper, Juniperus phoenicea. It consists of flat and rounded rocky outcrops, providing ample crevices, surrounded by open areas with scattered shrubs of Artemisia sieberi and small rocks (Fig. 7). Surrounding the area, Sandstone Mountains stand high forming the Petra sandstone enclave. At one particular site, 20 specimens, including what seemed to be gravid females, were collected. Scorpions were found under stones. Orthochirus scrobiculosus (Grube, 1873) was also found in the same area together with the Buthus specimens. At another site, less than $200 \mathrm{~m}$ from the first location, only specimens of Leiurus hebraeus (Birula, 1908) were found. Previously, only the following species were collected from Petra area: Androctonus bicolor Ehrenberg, 1828, Compsobuthus werneri (Birula, 1908), Leiurus hebraeus and Nebo hierichonticus (Simon, 1872).

\section{Habitat of Buthus amri (Fig. 8)}

This species was collected from Wadi Rum area $\left(29^{\circ} 34^{\prime} 14^{\prime \prime} \mathrm{N}, 35^{\circ} 17^{\prime} 00^{\prime \prime} \mathrm{E}\right)$, in a more arid area of granite mountains (less than $150 \mathrm{~mm}$ of rain annuallly). It inhabits hard sandy soil with sparse bushes (Lourenco et al. 2010). From a biogeographical classification perspective, the area is within Sudanian Penetration region that prevails in southern Jordan. Few Acacia trees can be observed within the area. To the east, the Wadi Rum sandstone formation is evident, with sandy corridors between the mountains (Fig. 8). Other scorpions found in Wadi Rum include Androctonus bicolor, Androctonus crassicauda (Olivier, 1807), Buthacus leptochelys (Ehrenberg, 1829), Orthochirus scrobiculosus, Nebo hierichonticus and Scorpio 
sp. As for the previous regions, the precise identifications of these species will be the subject of new studies.

\section{Biogeographic considerations}

According to Avni (2008) the process of aridification and continental soil erosion in the arid and semi-arid regions of the Middle East is the result of long-term, natural dynamic changes in the soil/rock ratio that evolved within drainage basins through time. This ongoing process is related to the continuous adjustment of the geomorphologic system to the interglacial climate and has been active mainly since the termination of the last glacial phase in the Late Pleistocene. Subsequently, during the present Holocene climate, these Late Pleistocene sediments within drainage basins have been largely removed. This ongoing process causes the degradation of soil and biomass and severely reduces the biotic potential of numerous portions of this region. These parameters indicate that a long-term natural desertification process is ongoing in the arid environment of the Middle East.

Also, according to Butzer (1975), the last interglacial period, even if poorly recorded in most areas, experienced environmental conditions similar to those of today. The last glacial episode allows characterization of at least three distinct palaeoclimatic provinces in the Near East. One of these, the Levant, experienced moderately cold and relatively dry climates in the north and cool and comparatively moist climates in the south. The mid-Holocene saw repeated moister trends in Egypt and Arabia, comparable to those in sub-Saharan Africa that most certainly affected Jordan and Israel but are not evident farther north (Butzer, 1975). All of the climatic changes recorded were short, and none exceeded the duration of the standard late Pleistocene sub stages.

Consequently, it is possible to suggest that the process of aridification of the Middle East deserts took place even during relatively recent times partially influenced by the changes in the Sahara region. These palaeoclimatic episodes probably lead to the isolation of the North and South Buthus populations in Jordan, acting as a dynamic speciation process.

\section{Acknowledgements}

We are most grateful to Elise-Anne Leguin (MNHN - Paris) for producing the habitus photos Buthus amri. 


\section{References}

Avni, Y. (2008): Glacial-Interglacial cycles, soil erosion and natural desertification in the Middle East. In: Sediment dynamics in changing environments. IAHS Publications, 325: $383-$ 390.

Butzer, K. W. (1975): Patterns of environmental change in the Near East during the late Pleistocene and early Holocene times. Pp. 389-410, In: Wendorf F. \& Marks A. E. (eds.). Problems in prehistory: North Africa and the Near East. Southern Methodist University Press, Dallas.

Hjelle, J. T. (1990): Anatomy and morphology. p. 9-63. In: G. A. Polis (Ed.), The Biology of Scorpions. - Stanford Univ. Press, 587 pp.

Levy, G. \& P. Amitai (1980): Fauna Palaestina, Arachnida I: Scorpiones. Israel Academy of Sciences and Humanities, Jerusalem, 130p.

Lourenço, W. R. (2002): Considérations sur les modèles de distribution et différentiation du genre Buthus Leach, 1815, avec la description d'une nouvelle espèce des montagnes du Tassili des Ajjer, Algérie (Scorpiones, Buthidae). - Biogeographica 78 (3): 109-127.

Lourenço, W. R. (2003): Compléments à la faune de scorpions (Arachnida) de l'Afrique du Nord, avec des considérations sur le genre Buthus Leach, 1815. - Revue suisse de Zoologie 110 (4): 875-912.

Lourenço, W. R. (2008): About the presence of the genus Buthus Leach, 1815 in the Arabian Peninsula and description of a new species (Scorpiones, Buthidae). - Entomologische Mitteilungen aus dem Zoologischen Museum Hamburg 15 (179): 45-52.

Lourenço W. R., Yağmur E. A. \& Duhem B. (2010): A new species of Buthus Leach, 1815 from Jordan (Scorpiones: Buthidae). - Zoology in the Middle East, 49: 95-99.

Lourenço, W. R., Wilmé, L. \& Waeber, P. O. (2018): Two more new species of Grosphus Simon, 1880, associated to the 'Grosphus simoni group' (Scorpiones: Buthidae) from the regions of the Bemaraha Tsingy and Montagne d'Ambre. - Revista Ibérica de Aracnologia, 32: $73-80$.

Lourenço, W. R., El-Bouhissi, M. \& Sadine S. E. (2020): Further considerations on the Buthus Leach, 1815 species present in Algeria and description of a new species (Scorpiones: Buthidae). - Revista Ibérica de Aracnologia, 36: 103-108.

Sousa, P., Arnedo, M. A. \& Harris, D. J. (2017): Updated catalogue and taxonomic notes on the old-world scorpion genus Buthus Leach, 1815 (Scorpiones, Buthidae). - ZooKeys, 686: 15-84.

Stahnke, H. L. (1970): Scorpion nomenclature and mensuration. - Entomological News 81: 297-316. 
Vachon, M. (1952): Etudes sur les scorpions. - Publications de l'Institut Pasteur d'Algérie, $482 \mathrm{pp}$.

Vachon, M. (1963): De l'utilité, en systématique, d'une nomenclature des dents des chélicères chez les Scorpions. - Bulletin du Muséum national d'Histoire naturelle, Paris, 2e sér., 35 (2): 161-166.

Vachon, M. (1974): Etude des caractères utilisés pour classer les familles et les genres de Scorpions (Arachnides). 1. La trichobothriotaxie en arachnologie. Sigles trichobothriaux et types de trichobothriotaxie chez les Scorpions. - Bulletin du Muséum national d'Histoire naturelle, Paris, 3e sér., nº 140, Zool. 104: 857-958.

Vachon, M. (1975): Sur l'utilisation de la trichobothriotaxie du bras des pédipalpes des Scorpions (Arachnides) dans le classement des genres de la famille des Buthidae Simon. Comptes Rendus des Séances de l'Académie de Sciences 281 (D): 1597-1599. 


\section{Caption to figures}

Fig. 1. Buthus amri. A-B. Male holotype. C-D. Female paratype.

Fig. 2. Buthus nabataeus sp. n. A. Female holotype. B. Male paratype, alive in laboratory.

Fig. 3. Buthus nabataeus sp. n. Photos under UV light. A. Female paratype. B-C. Ventral aspect of female and male paratypes showing coxapophysis, sternum, genital operculum, pectines and sternites. D-E. Metasomal segments in detail, showing carinae on lateral and ventral aspects.

Fig. 4. Buthus nabataeus sp. n. Female paratype A. Metasomal segments and telson, lateral aspect, showing huge carination. B-C. Movable and fixed fingers showing rows of granules.

Fig. 5. Buthus nabataeus sp. n., female holotype (A-D, F). Buthus amri, female paratype (E). Trichobothrial patterns. A. Femur, dorsal aspect; B-C. Patella, dorsal and external aspects. DF Chela, ventral and dorso-external aspects (scale bar $=1 \mathrm{~mm}$ ).

Fig. 6. Buthus nabataeus sp. n., female holotype and male paratype (B-D). Buthus amri, female paratype (A). A-B. Chelicera, dorsal aspect. C-D. Metasomal segments and telson, lateral aspect of female holotype and male paratype.

Figs. 7-8. The natural habitat of Buthus nabataeus sp. n. and Buthus amri. 